\title{
Gear Shift Control of 2-Speed Electric Vehicle with Backlash
}

\author{
Zhanjiang Li1, Shu Li2, Jun Li1 Xuesong Li1 \& Bingzhao Gao1* \\ 1 College of Automotive Engineering, Jilin University, Changchun 130025, P.R. China
}

2 Air Force Aviation University, P.R. China

*Corresponding Author: gaobingzhao@hotmail.com

Keywords: electric vehicle, 2-speed AMT, gear shifting, motor torque control, backlash.

\begin{abstract}
This paper deals with the gear shift control of 2-speed AMT driving system of Electric Vehicle with gear backlash. A motor torque control strategy is proposed to eliminate the impact of gear backlash when adjust the speed of the driving system. The proposed control strategy is confirmed through simulation tests on a complete power train simulation model. The simulation results show that it can reduce the impact of the gear backlash.
\end{abstract}

\section{Introduction}

Backlash is a common phenomenon in many systems. Especially in gear systems this is a problem which very often occurs, and is a drawback when constant angular velocity is desired.

In a transmission system with backlash, when the driving gear changes direction or the traction torque changes from positive to negative, the driven gear will be uncontrollable due to the existence of backlash. The driven gear cannot be controlled by the driving gear until the driving and driven gears contact again, which yields tracking error. Meanwhile, due to the existence of backlash, the relationship between the output shaft and the input shaft in the transmission system becomes nonlinear, which complicates the control task of such system. Moreover, when the driving gear and the driven gear contact again, there will be an impact which does harm to the tracking performance of the system. All the above mentioned factors will cause adverse effects on the control precision of the transmission system [1].

In order to describe the backlash phenomenon between the gears, different mathematical models were proposed, such as an inverse backlash model based on a hysteresis cycle [2], a differentiable model based on the dead zone characteristic [3], and a describing function described the no-linear backlash [4] and so on. Moreover, some control solutions have also been proposed, the paper [1] proposed a robust switching control strategy for a transmission system with unknown backlash. In the contact mode, the system adopts a linear controller. In the backlash mode, the system adopts a composite controller which uses linear controller and backlash compensation controller together to eliminate the nonlinearity. The paper [5] studied the influence and the partial compensation of simultaneously acting backlash and Coulomb friction in a speed and position control of an elastic two-mass system. Paper [6] developed a nonlinear observer for systems with backlash, based on the estimation of the disturbed torque transmitted due the dead zone, designed an adaptive controller using this non-linear observer to compensate the disturbed torque on line. Paper [7] proposed a torque controller for motor which consists of a PID controller, proportional feed-forward compensation, and proportional feedback compensation of the gear torque estimated by a disturbance observer. The paper [8] proposed a speed control method of a drive system with gear backlash which consists of a PI controller and PD feedback compensation of the gear torque estimated by a disturbance observer.

Most of the literatures on the backlash control focus on the speed or position control. In powertrain applications of backlash control, it is important with torque control. The reason is that transients where the backlash is involved are faster in comparison to the vehicle's speed transients. Therefore, speed can be considered as constant in the backlash control time scale [9].

This paper deals with the gear shift control of 2-speed AMT driving system of Electric Vehicle with gear backlash. A motor torque control strategy is proposed to eliminate the impact of gear 
backlash when adjust the speed of the driving system. The motor torque reduced to adjust the clutch slipping speed actively. Meanwhile the driving and driven gears teeth are controlled in a state of suspension and no traction torque transferred between the gears, in order to avoid impact force when the driving and driven gears contact again. Finally, the proposed control strategy is confirmed through simulation tests on a complete power train simulation model. The simulation results show that it can reduce the impact of the gear backlash.

The paper is organized as follows. In the next section, we propose the model that we research in this paper, and the gear shift process and the control objectives are described in detail. In Section 3, the control strategy is presented. Section 4 presents the simulation tests on on a complete powertrain simulation model. Finally, we conclude our paper in section 6.

\section{Powertrain and problem statement}

The structure diagram of electric vehicle powertrain system is illustrated in Fig.1.

The gear shift process is divided into torque phase and inertia phase. During the up-shift process, firstly, the clutch engages gradually, the output torque of the traction motor is transferred from synchronizer to clutch, so the torque from synchronizer is reduced. When it is zero, the synchronizer is released. Then into inertia phase, keep the clutch torque unchanged, at the same time reduce motor speed to complete the synchronization of clutch discs, and then the clutch is locked up, complete the up-shift process. The downshift is approximately regarded as a reverse process of the up-shift [10].

During the process of adjustment of clutch slipping speed, the motor torque reduced to adjust the clutch speed actively. However, the motor torque may be reduced from positive to negative, this produce a problem. Due to the existence of backlash, the driving and driven gears separated then contact again, there will produce an impact noise which influences the comfort performance of the driving system, and the driven gear speed is difficult to control which influence the synchronization of the clutch.

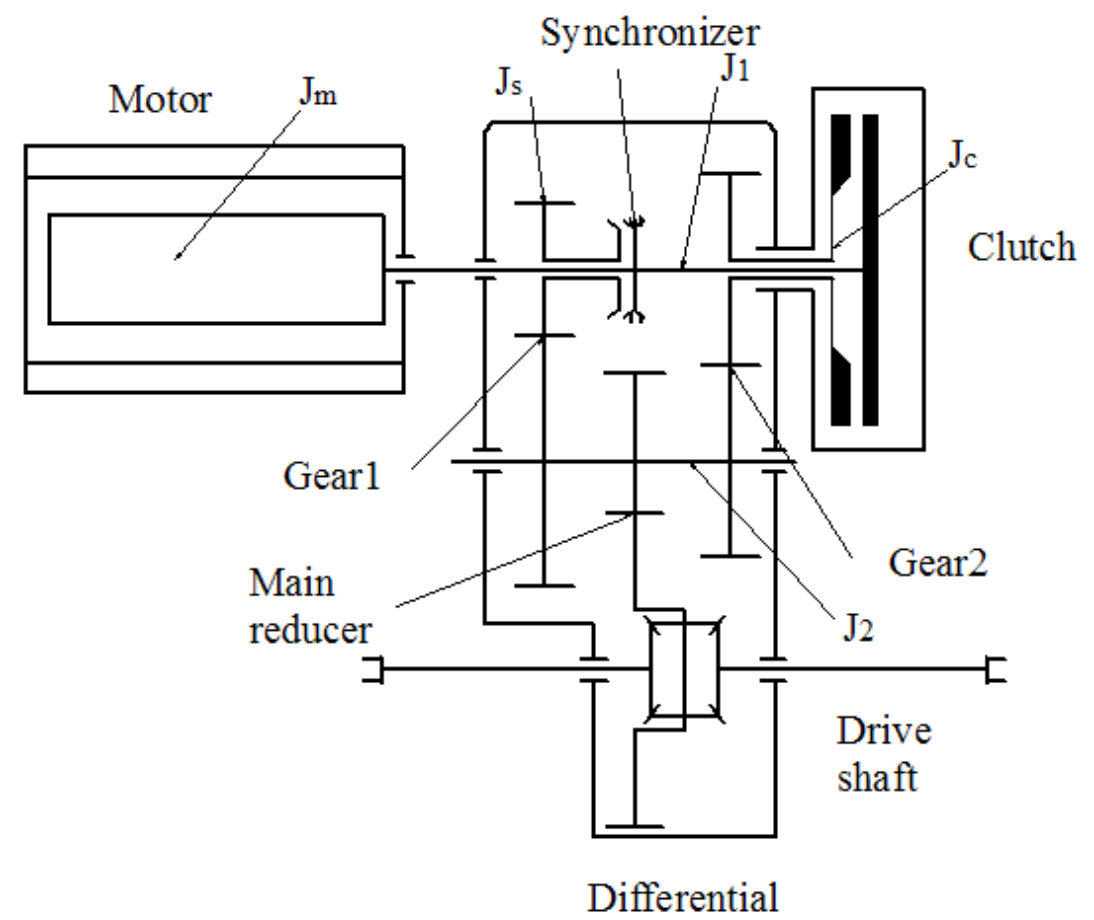

Fig.1. The structure diagram of the powertrain

\section{Analysis of the control strategy}


In this paper, the backlashes of the whole driving system are cumulated in the side of the traction motor as shown in Fig.2. We set the backlash to 10 degree (about $3.5 \mathrm{~mm}$ in the circumferential direction of the pitch circle), that is $2 \triangle=3.5 \mathrm{~mm}$ as shown in Fig.3.

According to our previous work, in the torque phase, the feed-forward control law is obtained, while in the inertia phase, optimal control is used to generate the reference trajectories of the clutch slip speed and motor torque [10]. From the simulation results we can see that in the condition of $25 \%$ acceleration demand, the motor torque reduced from positive to negative then to positive in the inertia phase. Due to the existence of backlash, the driving and driven gears separated then contact again, there will produce an impact noise which influences the comfort performance of the driving system, and the driven gear speed is difficult to control which influence the synchronization of the clutch.

Therefore, we propose a torque control strategy of the traction motor, the driving and driven gears teeth are controlled in a state of suspension and no traction torque transferred between the driving and driven gears. That is to say, during the process of synchronization of the clutch, reduce the motor torque to keep the driven gear teeth can't contact to another side of the driving gear teeth and no contact force between the gears teeth. For example, in Fig. 3 the driven gear can only contact to the point $\mathrm{P}$ and can't contact to the point $\mathrm{Q}$. Thus, avoid the impact noise and improve the comfort performance of the gear shifting.

In order to achieve this control effect, the motor output torque should meet the dynamic balance equation as follows:

$$
T_{m}-J_{m} \dot{\omega}_{m}=0 \text {. }
$$

Based on the motor speed, the motor desired output torque can be obtained as:

$$
T_{m}^{*}=J_{m} \dot{\omega}_{m} .
$$

So there is no torque effect on the driven gear.

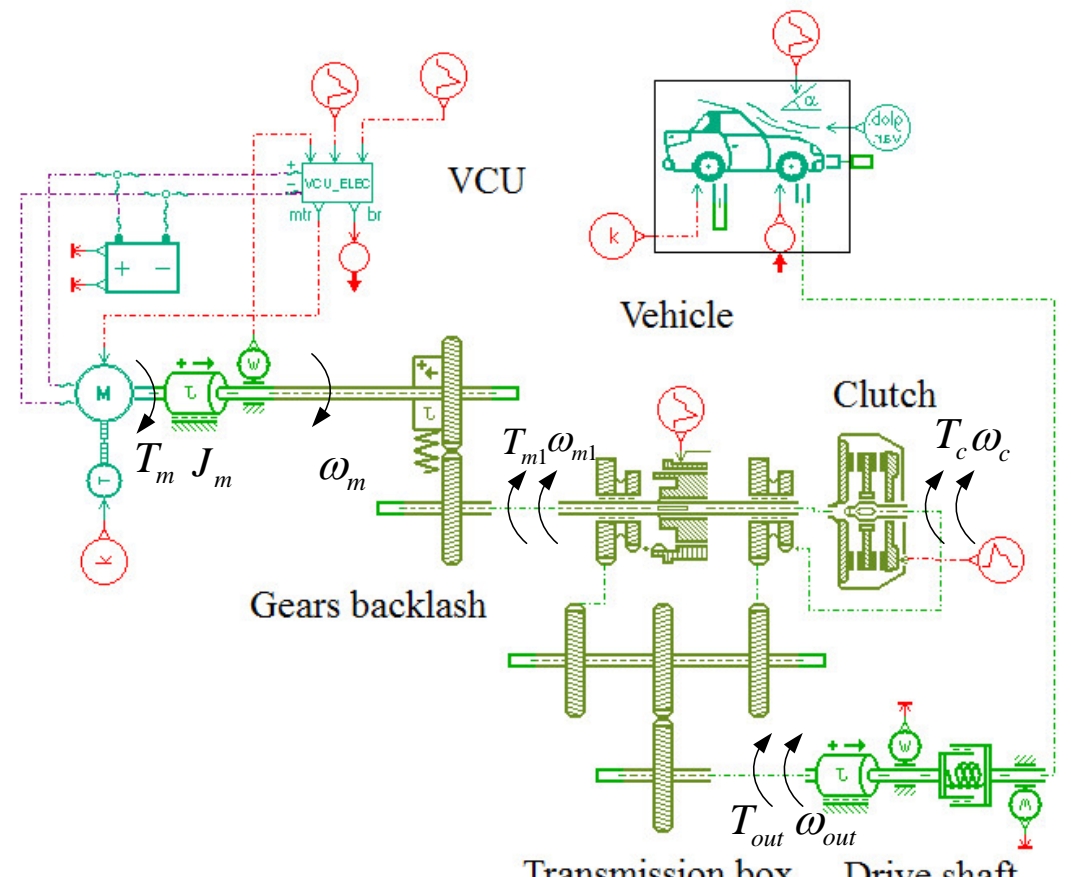

Transmission box Drive shaft

Fig.2. The simulation model of the powertrain 


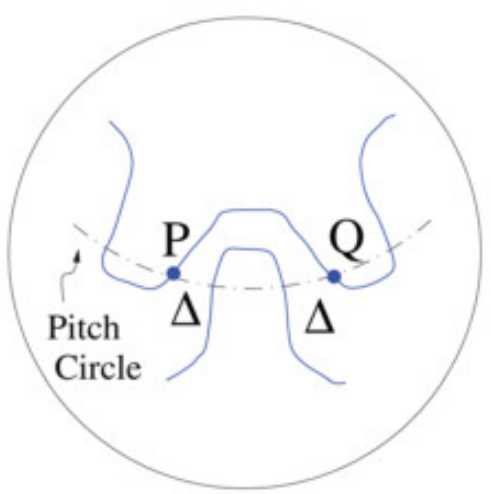

Fig.3. The schematic diagram of the gear backlash

\section{Simulation tests}

The proposed control strategy is tested on a complete powertrain simulation model as shown in Fig.2. In the condition of $25 \%$ acceleration demand, the up-shift process was analyzed and the results of three situations are given in Fig.4, Fig.5 and Fig.6. Which are: without consideration of backlash [10], with backlash but without the proposed control strategy and with the proposed control strategy.

From the simulation results, it can be seen that due to the gear backlash, when the motor torque changes from positive to negative it produces significant impact force between the gears as shown in the top of the Fig.5, and the speed of the transmission primary shaft vibrated significantly. So it is difficult to synchronize the clutch slipping speed, when engage the clutch, it produces additional vibration. In Fig.6, with the control strategy, the motor torque reduced to negative but the gears doesn't transfer the negative torque, so the driven gear can't contact the other side of the driving gear, and it doesn't produce undesired impact, and it can be seen from the relative linear displacement of the driving and driven gears in Fig.7. And the transmission output changed smoothly; the vehicle jerk $d a$ was very small in Fig.6. These can prove that the proposed control strategy can achieve comfort gear shift with gear backlash.

\section{Conclusions}

The gear shift process of 2-speed AMT powertrain of Electric Vehicle with gear backlash is analyzed. When the motor torque changes from positive to negative it produces significant impact force between the gears. So a motor torque control strategy is proposed to eliminate the impact of gear backlash when adjust the speed of the clutch. The driving and driven gears teeth are controlled in a state of suspension and no traction torque transferred between the gears. Finally, the proposed control strategy is confirmed through simulation tests on a complete powertrain simulation model. The simulation results show that it can reduce the impact of the gear backlash. 

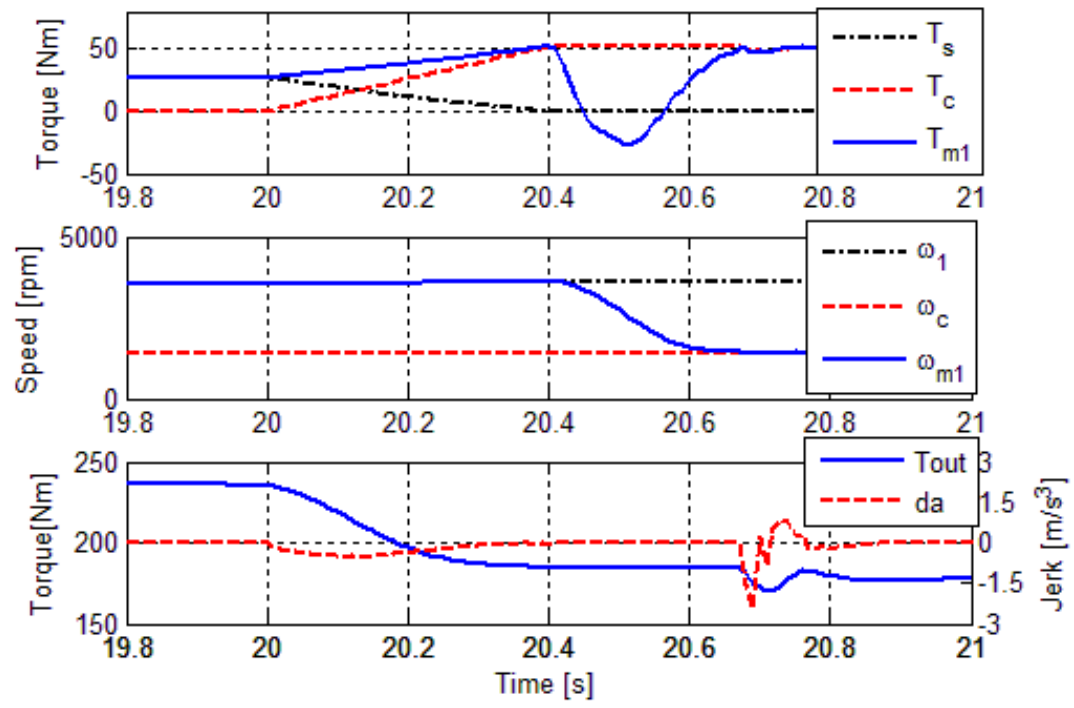

Fig.4. The results of gear shift without backlash
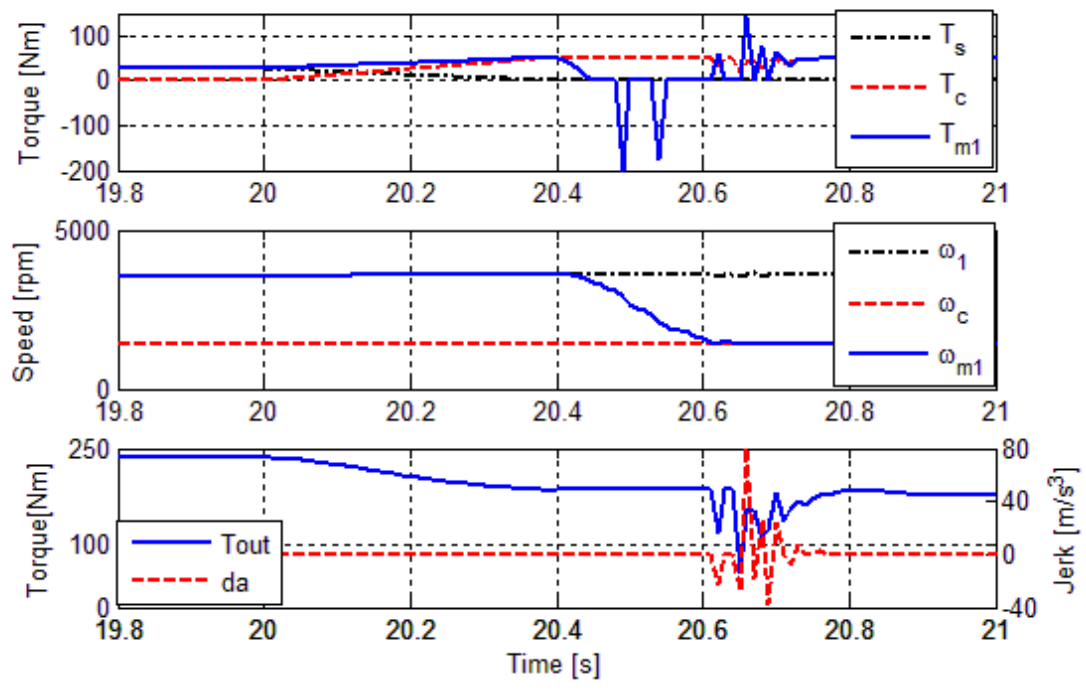

Fig.5. The results of gear shift with backlash
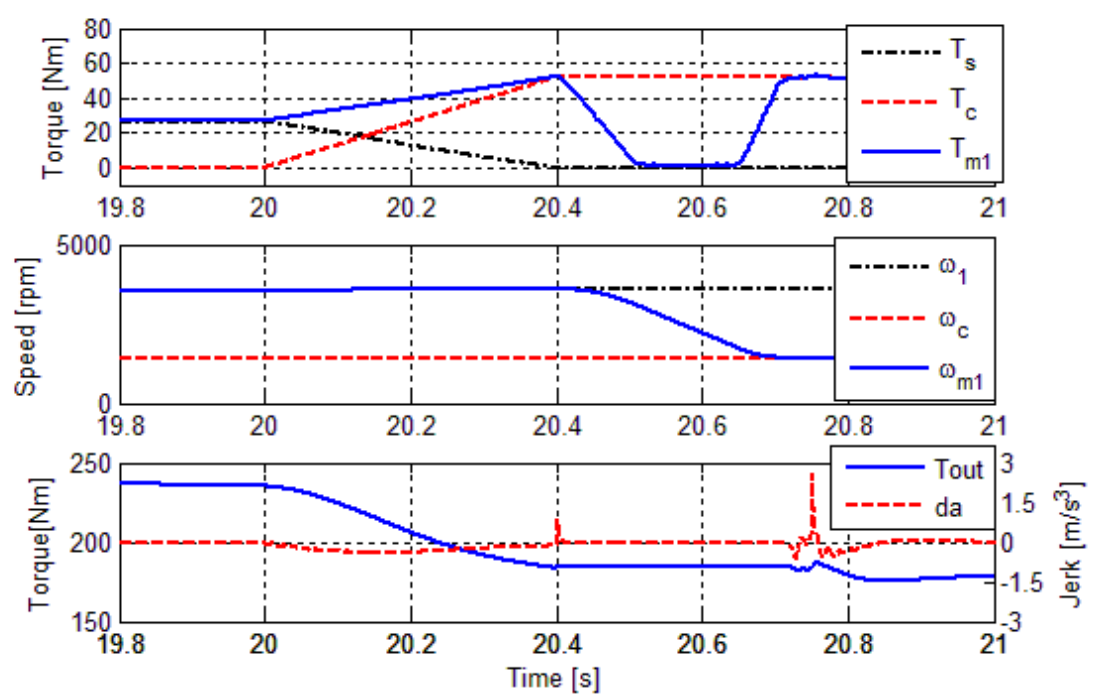
Fig.6. The results of gear shift with the proposed controller

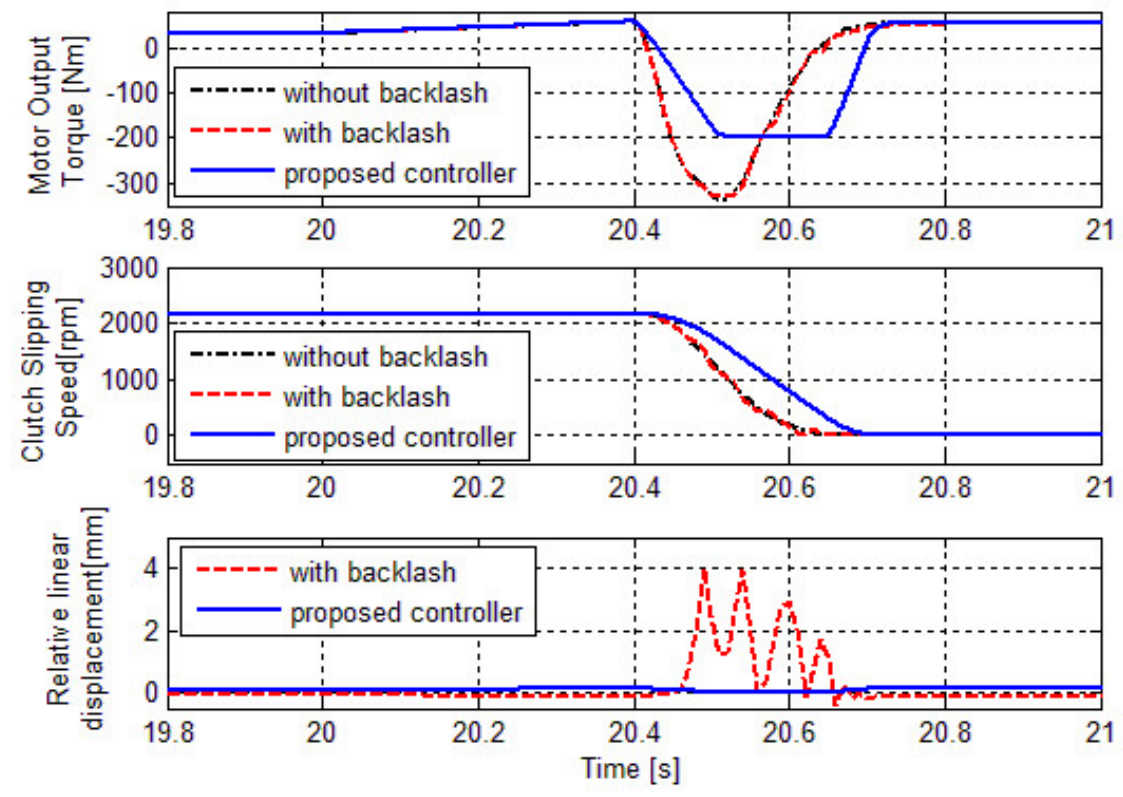

Fig.7. The comparison of the three situations

\section{Acknowledgements}

This work is supported by the National Nature Science Foundation of China (61374046) and by the Jilin Provincial Science \& Technology Department (No. 20130522183JH, 20150204056GX).

\section{References}

[1] Ling, Q., Yan, Z., Shen, H., Li, J., and Wang, Y. Robust Switching Control Strategy for a Transmission System with Unknown Backlash. Mathematical Problems in Engineering, 2014.

[2] Tao, G., and Kokotovic, P. V. Adaptive control of systems with backlash. Automatica, 29(2), 323-335, 1993.

[3] Cadiou, J. C., and N. K. M'Sirdi. Modelization and analysis of a system with torque transmitted through a backlash. 9th World Congress on the Theory of Machines and Mechanisms, Milan. 1995.

[4] Smith M.C. Nonlinear and predictive control: Describing functions 2004

[5] Brandenburg, G., and U. Schäfer. Influence and Partial Compensation of Simultaneously Acting Backlash and Coulomb Friction in a Speed-and Position-controlled, Elastic Two-mass System,1988.

[6] Merzouki, R., J. C. Cadiou, and N. K. M'Sirdi. Compensation of backlash effects in an electrical actuator. The IASTED international conference on intelligent systems and control. 2000.

[7] Nakayama, Y., Fujikawa, K., and Kobayashi, H. A torque control method of three-inertia torsional system with backlash. In Advanced Motion Control, 2000. Proceedings. 6th International Workshop on IEEE, pp. 193-198, 2000.

[8] Wu, Y., Fujikawa, K., and Kobayashi, H. A control method of speed control drive system with backlash. In Advanced Motion Control, AMC'96-MIE. Proceedings.,4th International Workshop on IEEE, Vol. 2, pp. 631-636,1996.

[9] Lagerberg, A. A literature survey on control of automotive powertrains with backlash. Chalmers tekniska högsk, 2001. 
[10]Liang, Q., Tang, N., Gao, B., and Chen, H. Optimal planning of the clutch slipping control for gear shift of 2-speed electric vehicle. Control and Decision Conference (2014 CCDC), The 26th Chinese. IEEE, pp.1538-1543, 2014. 